catecholamines associated with a severe infarction (Valori et al., 1967; Wallace and Klein, 1968) may have predisposed these patients to serious arrhythmias. A typical "late sudden death" patient reported by Jewitt et al. (1969) had ventricular fibrillation on the 12th day after severe infarction and excessively high urine levels of noradrenaline and adrenaline up to the 11th day.

\section{CHOICE OF PATIENTS FOR MONITORING}

Though the causes of late cardiac arrest and sudden death in hospital remain unclear, these catastrophes occur in nearly $10 \%$ of patients expected to leave hospital alive. The current role of the coronary care unit in monitoring only the first few days after infarction may need re-examination.

It is clearly impossible to continue monitoring for several weeks every patient who is admitted to the unit. Our data indicate that those patients exhibiting the risk factors of anterior infarction, severe infarction, persistent sinus tachycardia, and early ventricular arrhythmias should be carefully sought and then selected for close and prolonged observation. The method of observation depends on the availability of staff and the sophistication of monitoring equipment available. Telemetering devices are not yet far enough advanced for their routine use in every patient; furthermore, treatment of premonitory arrhythmias may be delayed if trained staff are not near the patient. Monitoring of patients in an open ward is ineffective in our experience and in that of others (Hubner et al., 1969; Rawles and Crockett, 1969). The solution must lie in extension of the present coronary care unit concept to allow the higherrisk patient to begin his psychological readjustment and rehabilitation in an area where he is close to the unit staff and is kept under close, but less obtrusive, general and electrocardiographic observation. How long this second-stage coronary care should continue poses an administrative problem. We recorded late sudden death in the third and fourth weeks of hospital stay, and it is possible that some patients will have to be monitored for several weeks. Such second-stage coronary care units should help further reduce the hospital mortality from acute myocardial infarction.

During the preparation of this paper, preliminary successful results from such a unit were reported (Grace and Yarvote, 1971). Information from these units will be relevant to the general problem of identifying which patients with coronary artery disease are susceptible to sudden death. Data accumulation on this question is limited by a relatively low frequency of the catastrophe outside hospital and ignorance of the precipitating arrhythmia thought to be responsible in most cases (Kuller, 1969). By careful monitoring of a group of patients known to be at high risk from sudden death, the relative importance of various risk factors can be evaluated.

We wish to thank Miss Janice Ferguson for secretarial help and Professor R. R. H. Lovell, Professor F. Epstein, and Dr. M. A. Rockwell for valuable comments and criticisms.

This work was supported by grants from U.S. Public Health Service, Heart Disease Central Programme, and the Life Officers Medical Research Fund.

\section{References}

Denborough, M. A., Lovell, R. R. H., Nestel, P. J., and Goble, A. J. 1968). Lancet, 1, 386

Grace, W. J., and Yarvote, P. M. (1971). American fournal of Cardiology, 26, 635 .

Hubner, P. J. B., Goldberg, M. J., and Lawson, C. W. (1969). British Medical fournal, 1,815 .

Jewitt, D. E., et al. (1969). Lancet, 1, 635

Julian, D. G., and Oliver, M. F. (1968). Acute Myocardial Infarction. Edinburgh, Livingstone.

Kuller, L. (1969). American fournal of Cardiology, 24, 617.

Lawrie, D. M. (1969). Lancet, 2, 1085.

Lown, B., Klein, M., and Hershberg, P. I. (1969). American fournal of Medicine, 46, 705 .

Norris, R. M., Brandt, P. W. T., Caughey, D. E., Lee, A. J., and Scott, P. J, (1969). Lancet, 1, 274

Pentecost, B. L., and Mayne, N. M. C. (1968). British Medical fournal, 1, 830.

Rawles, J. M., and Crockett, G. S. (1969)

Restiaux, N. et al (1967). Lancet, 1 , 1285.

Robinson, J. S. (1965). American Heart fournal, 69, 285

Rockwell, M. A. (1969). Memorandum RM-5944-12C, Rand Corporation, Santa Monica, California.

Sloman, J. G., and Brown, R. (1970). American Heart fournal, 79, 761.

Spracklen, F. H. N., Besterman, E. M. M., Everest, M. S., Litchfield, J. W., and Petrie, M. (1968). British Medical fournal, 4, 364.

Stannard, M., and Sloman, J. G. (1969). American Heart Fournal, 77, 573. Stock, E., Goble, A. J., and Sloman, J. G. (1967). British Medical fournal, 2, 719.

Thompson, P. L., Wain, C., and Sloman, J. G. (1971). Medical fournal of Australia, 1, 687

Valori, G., Thomas, M., and Shillingford, J. P. (1967). American fournal of Cardiology, 20,605.

Wallace, A.G., and Klein, R.F. (1969). American Fournal of Medical Sciences, $258,139$.

World Health Organization (1968). Regional Office for Europe. Working Group on Ischaemic Heart Disease, Report I. Copenhagen, W.H.O.

\title{
Bronchodilator Effect of Oral Salbutamol in Asthmatics Treated with Corticosteroids
}

\author{
SHEENA S. PARKER, Y. F. J. CHOO-KANG, E. JEAN COOPER, S. J. CAMERON, I. W. B. GRANT
}

British Medical fournal, 1971, 4, 139-142

\section{Summary}

In a double-blind trial the effect on ventilatory function of oral salbutamol (in two different doses) and a placebo were studied in 12 patients with chronic asthma receiving regular maintenance treatment with prednisolone. Salbutamol in a dose of $\mathbf{4} \mathbf{~ m g}$ four times daily, given for a

Respiratory Diseases Unit, Northern General Hospital, Edinburgh EH5 2DQ, and Department of Respiratory Diseases, University of Edinburgh

SHEENA S. PARKER, M.B., CH.B., Registrar

Y. F. J. CHOO-KANG, B.SC., M.R.C.P.ED., Registrar

E. JEAN COOPER, M.B., CH.B., Research Assistant

E. JEAN COOPER, M.B., CH.B., Research Assistant

S. J. CAMERON, M.B., M.R.C.P.ED., Senior Registrar period of four weeks, produced a sustained and statistically significant increase in peak expiratory flow rate over the pretreatment recordings. This effect was not observed with a lower dose of salbutamol $(2 \mathrm{mg}$ four times daily) or with a placebo. Salbutamol in the higher dose would seem to be an effective and safe oral bronchodilator that can be recommended for the treatment of mild or moderate asthma. The duration of treatment in this study was, however, limited to four weeks, and it is not known whether effective bronchodilatation would be maintained if the drug were given for longer periods.

\section{Introduction}

An effective long-acting oral bronchodilator with a wide margin of safety would have important advantages over aerosol pre- 
parations in the treatment of asthma. Oral bronchodilators can be administered in a therapeutic dose without loss of the variable and unknown quantity of the drug which occurs during inhalation. While oral drugs are normally prescribed according to a strict schedule which is followed by most patients, the "instant cure" appeal of an inhaler may lead to haphazard administration and excessive dosage.

Ephedrine was widely used for the relief of bronchospasm, but slow onset of action, unselective sympathetic stimulation, and tachyphylaxis limited its long-term use in many patients. More recently aerosols containing isoprenaline were generally prescribed. Isoprenaline is unsuitable for oral administration, and its undesirable cardiovascular side effects, intensification of hypoxia, and short duration of action prompted a search for more satisfactory oral bronchodilators. Orciprenaline, a resorcinol analogue of isoprenaline, proved to have minor selectivity for bronchial muscle with a corresponding slight reduction in cardiotoxicity (Engelhardt et al., 1961).

Salbutamol, another structural modification of isoprenaline, introduced in 1968, was found to be superior to orciprenaline in both respects (Brittain, 1971). Because of its powerful bronchodilator activity, prolonged action, and freedom from overt cardiovascular side effects in the recommended dose, it is considered by many the bronchodilator of choice when administered by metered aerosol or intermittent positive-pressure ventilation (Choo-Kang et al., 1969, 1970). Salbutamol, like orciprenaline, is effective by mouth, resisting both dealkylation and catechol-o-methyl transferase which rapidly inactivate isoprenaline. Peak plasma levels occur one to three hours after ingestion; after four hours about $50^{\circ}, 0$ of the dose has been excreted in the urine, the proportion reaching $90^{\circ}{ }_{0}^{\circ}$ in 24 hours (Kennedy and Simpson, 1969). These observations correspond with those of Kamburoff and Prime (1970), who showed that bronchodilation after oral salbutamol $(5 \mathrm{mg}$ ) increased to a maximum at one hour and was still present at five hours. The effect of $5 \mathrm{mg}$ by mouth was similar to that of $200 \mathrm{~kg}$ by inhalation, and the larger oral dose was not associated with any increase in unwanted effects.

It was therefore decided in this study to investigate the longterm bronchodilator effect of oral salbutamol in chronic asthmatics taking regular corticosteroid therapy. To overcome the difficulties presented by fluctuations in the degree of asthma, outpatients with a reasonably stable level of airways obstruction were selected for the investigation. Because of the length of the study, all patients measured the peak expiratory flow rate (PEFR) at home with a Wright Peak Flow Meter, as in studies reported by Heaf and Mattila (1969) and Epstein et al. (1969).

\section{Method of Investigation}

Patients were studied for three consecutive four-week periods. The preparations used were (1) 4-mg salbutamol tablets, (2) 2-mg salbutamol tablets, and (3) placebo tablets, all identical in appearance and taste. All 12 patients received each of these preparations in random order for periods of four weeks. The tablets were packed so that two weeks' supply could be issued at a time. The packs were coded to conceal their identity from both patient and doctor.

All the patients were taking prednisolone on Tuesday, Wednesday, and Thursday of each week. They entered the trial on a Tuesday (to coincide with the first day of corticosteroid therapy for that week) and were subsequently reviewed fortnightly on Mondays. A week before the trial any oral bronchodilators and aerosols used by the patient were withdrawn.

Each patient was provided with a metered aerosol delivering isoprenaline (Medihaler Iso) for use as necessary (except during the hour preceding the recording of a PEFR). Isoprenaline was selected because of its short duration of action, to influence as little as possible the next recording of PEFR.

Each patient was provided with a Wright Peak Flow Meter for the duration of the trial. A record card was issued to cover
TABLE I-Scale Used for Personal Assessment of Asthma

\begin{tabular}{|c|c|c|}
\hline & Day & Night \\
\hline A. Terrible & $\begin{array}{l}\text { Unable to move about- } \\
\text { very breathless }\end{array}$ & Kept awake most of the \\
\hline B. Very bad & $\begin{array}{l}\text { Able to walk about the house } \\
\text { very slowly but becoming } \\
\text { very breathless }\end{array}$ & $\begin{array}{l}\text { Wakened by asthma almost } \\
\text { hourly but able to sleep } \\
\text { in between attacks }\end{array}$ \\
\hline $\begin{array}{l}\text { C. Moderately } \\
\text { bad }\end{array}$ & $\begin{array}{l}\text { Able to climb stairs slowly } \\
\text { but not to walk at a } \\
\text { normal pace }\end{array}$ & $\begin{array}{l}\text { Wakened } 4-6 \text { times by } \\
\text { asthma, but sleeping be- } \\
\text { tween attacks }\end{array}$ \\
\hline D. Slightly & $\begin{array}{l}\text { Able to walk outside at } \\
\text { normal pace but cannot } \\
\text { hurry }\end{array}$ & $\begin{array}{l}\text { Wakened } 2-3 \text { times-other- } \\
\text { wise sleeping well }\end{array}$ \\
\hline $\begin{array}{l}\text { E. Moderately } \\
\text { well }\end{array}$ & $\begin{array}{l}\text { Able to hurry but unable to } \\
\text { run short distances with- } \\
\text { out becoming very }\end{array}$ & $\begin{array}{l}\text { Wakened once by asthma- } \\
\text { otherwise sleeping well }\end{array}$ \\
\hline F. Very well & $\begin{array}{l}\text { Able to hurry without } \\
\text { feeling uncomfortable }\end{array}$ & $\begin{array}{c}\text { Sleeping throughout the } \\
\text { night }\end{array}$ \\
\hline
\end{tabular}

each two-week period, and ability to use the flow meter correctly was carefully checked. The best of three PEFR measurements was recorded at 8 a.m., 6 p.m., and 8 p.m. daily. A personal assessment of the severity of asthma in the preceding 12 hours was also made at 8 a.m. and 8 p.m. with a six-point scale (Table I), and the number of occasions on which the isoprenaline aerosol had been used during that period was recorded. Tablets were taken at 8 a.m. (after the PEFR measurement), 12 noon, 4 p.m., and 10 p.m. The PEFR was recorded thrice daily for seven days before the start of treatment and the mean of these figures was designated "pretreatment" peak flow rate. This was then compared with the figures obtained during each four-week period of the trial.

\section{Patient Selection}

Twelve patients ( 10 women and 2 men) were studied. Their ages ranged from 19 to 67 (mean 42.5) years. All had chronic asthma which was adequately controlled by intermittent corticosteroid therapy in the form of prednisolone administered on three consecutive days per week in a dose of $7 \cdot 5-20 \mathrm{mg}$ daily, and they had been established on this regimen for at least six months. Each patient was known to respond well to sympathomimetic drugs in reversibility studies, but over the previous 12 months the forced expiratory volume had usually been well below the patient's previous best recording; scope for improvement in PEFR was, therefore, present in all patients during the period of study.

\section{Results}

\section{GENERAL OBSERVATIONS}

Eleven out of 12 patients completed the trial. One (Case 3) fractured three ribs in a fall nine weeks after starting the trial; she was subsequently unable to use the peak flow meter, and was therefore withdrawn. The PEFR measurements obtained before her withdrawal were, however, included in the analysis. All patients completed their record cards conscientiously.

Five patients (Cases 4, 5, 7, 9, and 11) found it necessary to increase the dose of prednisolone temporarily during the 12week period, three while taking the 2-mg dose of salbutamol and two while taking placebo. No patient had to increase the dose of prednisolone while taking the 4-mg dose of salbutamol.

\section{RESULTS OF PEFR RECORDINGS}

The mean differences between the readings obtained at 8 a.m., 6 p.m., and 8 p.m. during weeks 2, 3, and 4 of each treatment period, and the corresponding figures for the pretreatment period, are shown in Table II. The readings obtained during week 1 of the second and third four-week periods could have been influenced by the treatment given during the previous 
TABLE II-Mean Differences between PEFR (with Standard Errors) Recorded during Weeks 2, 3, and 4 of Trial and Those of the Pretrial Period

\begin{tabular}{|c|c|c|c|c|c|c|}
\hline \multirow{2}{*}{ Time } & \multicolumn{2}{|c|}{ Placebo } & \multicolumn{2}{|c|}{ Salbutamol $2 \mathrm{mg}$} & \multicolumn{2}{|c|}{ Salbutamol $4 \mathrm{mg}$} \\
\hline & & $\mathbf{P}$ & & $\mathbf{P}$ & & $\mathbf{P}$ \\
\hline & & & i & & & \\
\hline \multicolumn{7}{|c|}{ Week 2} \\
\hline $\begin{array}{l}8 \text { a.m. } \\
6 \text { p.m. } \\
8 \text { p.m. }\end{array}$ & $\begin{array}{r}6.4(11.2) \\
11.4(10.9) \\
8.3(13.5)\end{array}$ & $\begin{array}{l}\text { N.S. } \\
\text { N.S. } \\
\text { N.S. }\end{array}$ & $\begin{array}{r}1.1(10.3) \\
18.0(11.2) \\
18.7(13.1)\end{array}$ & $\begin{array}{l}\text { N.S. } \\
\text { N.S. }\end{array}$ & $\begin{array}{l}23 \cdot 2(9 \cdot 9) \\
52 \cdot 4(11 \cdot 2) \\
48 \cdot 5(11 \cdot 0)\end{array}$ & $\mid \begin{array}{l}<0.05 \\
<0.001 \\
<0.001\end{array}$ \\
\hline \multicolumn{7}{|c|}{ Weck 3} \\
\hline $\begin{array}{l}8 \text { a.m. } \\
6 \text { p.m. } \\
8 \text { p.m. }\end{array}$ & $\begin{array}{l}8 \cdot 6(13 \cdot 2) \\
7 \cdot 7(11 \cdot 5) \\
8 \cdot 3(13 \cdot 0)\end{array}$ & $\begin{array}{l}\text { N.S. } \\
\text { N.S. } \\
\text { N.S. }\end{array}$ & $\begin{array}{r}5.9(12.6) \\
20 \cdot 6(13.3) \\
22 \cdot 8(17 \cdot 0)\end{array}$ & $\begin{array}{l}\text { N.S. } \\
\text { N.S. } \\
\text { N.S. }\end{array}$ & $\begin{array}{l}20 \cdot 1 \quad(9 \cdot 4) \\
45 \cdot 6 \quad(9 \cdot 2) \\
48 \cdot 4(10 \cdot 2)\end{array}$ & $\begin{array}{l}\text { N.S. } \\
<0.001 \\
<0.001\end{array}$ \\
\hline \multicolumn{7}{|c|}{ Week 4} \\
\hline $\begin{array}{l}8 \text { a.m. } \\
6 \text { p.m. } \\
8 \text { p.m. }\end{array}$ & $\begin{array}{l}4.7(11.0) \\
6.5(9.9) \\
5.7(11.7)\end{array}$ & $\begin{array}{l}\text { N.S. } \\
\text { N.S. } \\
\text { N.S. }\end{array}$ & $\begin{array}{r}6 \cdot 3(10 \cdot 6) \\
11 \cdot 3(10 \cdot 6) \\
18 \cdot 3(12 \cdot 8)\end{array}$ & $\begin{array}{l}\text { N.S. } \\
\text { N.S. } \\
\text { N.S. }\end{array}$ & $\begin{array}{l}16.9(10 \cdot 8) \\
43.2(10.6) \\
43.7(10 \cdot 9)\end{array}$ & $\begin{array}{l}\text { N.S. } \\
<0.005 \\
<0.005\end{array}$ \\
\hline
\end{tabular}

period. For this reason the week 1 readings in all three treatment periods were excluded from the analysis.

Placebo.-In all the periods during which placebo was given there was a slight, but not significant, increase in PEFR over the pretreatment value.

Salbutamol $2 \mathrm{mg}$.- None of the increases in PEFR recorded with $2 \mathrm{mg}$ of salbutamol achieved statistical significance at any time of day in any week, though the 6 p.m. and 8 p.m. figures were somewhat higher than those obtained with placebo.

Salbutamol $4 \mathrm{mg}$.-During week 2 of treatment with $4 \mathrm{mg}$ of salbutamol the increase in mean PEFR over the pretreatment figure achieved statistical significance at 8 a.m., 6 p.m., and $8 \mathrm{p} . \mathrm{m}$. In weeks 3 and 4 the 8 a.m. increase failed to achieve significance and the 6 p.m. and 8 p.m. increases were somewhat lower than those of week 2 , though still highly significant. This might be an example of tachyphylaxis, but when the figures for week 2 and week 4 for every treatment ("best" and "worst" weeks) were compared the decreases were not significant (Table III).

\section{EFFECT OF CORTICOSTEROIDS}

An attempt was made to assess the effect of treatment with prednisolone on the results. Since this drug was given on three consecutive days each week there were four occasions in each four-week trial period on which the effect of prednisolone could be observed, but as the first occasion coincided with a change in salbutamol treatment there were only three legitimate occasions during each period on which the effect of prednisolone could be
TABLE III-Decrease in Mean PEFR in Week 4 when Compared with Week

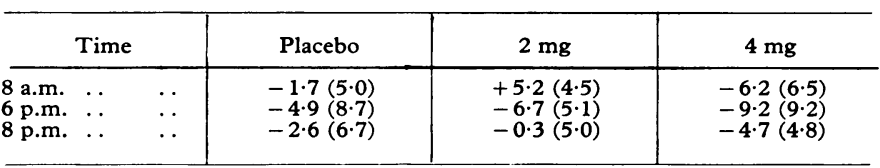

evaluated. The actual "effect" was defined as the PEFR on the third day of prednisolone treatment minus the PEFR on the day before it was started. This "effect" was statistically significant ( $P \pm 0.05$ ) only for the 8 a.m. figures recorded during periods on $4 \mathrm{mg}$ of salbutamol, and was presumably mediated by the dose of salbutamol taken 10 hours earlier-that is, at 10 p.m. on the previous evening.

\section{PERSONAL ASSESSMENT}

To summarize the patient's subjective response, the scale (Table I) was expressed numerically and an average calculated for each week. These scales were based solely on subjective assessment. If, however, they are treated as true measurements the standard error of the differences from the pretrial assessment indicates that the patients were significantly better on the 4-mg tablets. This agrees with the results of the PEFR measurements.

Inquiries into each patient's assessment of progress were made by the same observer at every review, and included a standard series of questions about possible drug side effects. Eight patients experienced tremor when taking 4-mg salbutamol tablets, seven when taking 2-mg salbutamol tablets, and three when taking placebo tablets. Only one patient (while on the higher dose of salbutamol) found this symptom persistently troublesome, but it was not necessary to withdraw treatment in this case or in any of the others. The patients did not complain of any other side effect. Eight out of 12 volunteered a strong preference for $4-\mathrm{mg}$ salbutamol tablets. Three others stated that placebo tablets were the least effective. The remaining patient expressed no preference for any of the treatments.

\section{INDIVIDUAL RESULTS}

Statistical processing tends to obscure the wide variation in the response of individual patients to a drug such as salbutamol. Table IV, which is included to illustrate this point, shows the range and mean PEFR during weeks 2-4 of each four-week period for each patient with details of age and pretrial PEFR. These figures show that there was a wide range of PEFR from day to day and also at different times of each day. Higher

TABLE IV-Details Of PEFR Recordings at 8 a.m. and 6 p.m. during Weeks 2-4 of Each Month of the Trial

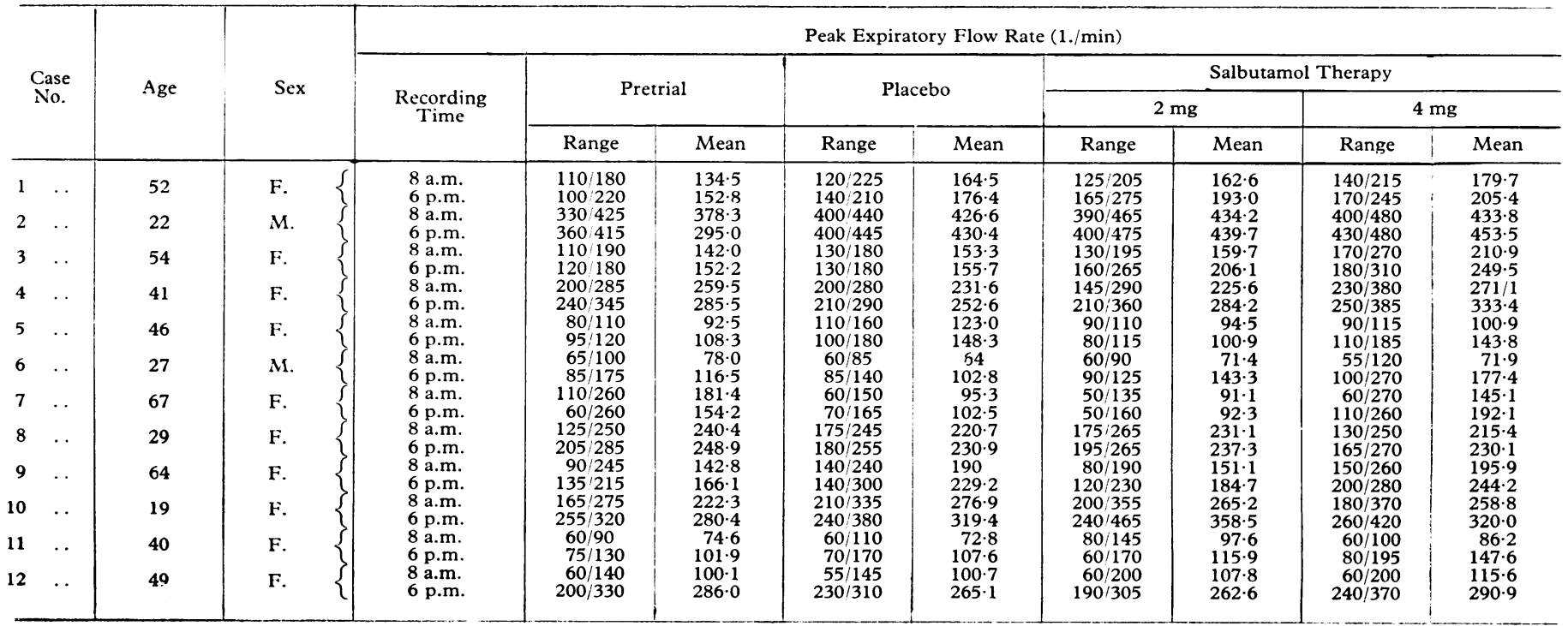


figures were usually recorded in the evening. The superiority of $4 \mathrm{mg}$ of salbutamol over the other two treatments was particularly evident when the 6 p.m. and 8 p.m. PEFR readings were compared with the pretreatment data in 11 out of 12 patients.

\section{Discussion}

In this study oral salbutamol, in a dose of $4 \mathrm{mg}$ four times daily, significantly increased the peak expiratory flow rate for up to four hours in outpatients on intermittent corticosteroid therapy. Most of these patients felt subjectively better while on this dose than when on a lower dose regimen or placebo. However, salbutamol in a dose of $2 \mathrm{mg}$ four times daily had no significant advantage over the placebo.

The almost complete failure to show a statistically significant improvement in PEFR at the end of each three-day spell of treatment with prednisolone is not surprising, since all the patients included in the study had been placed on this type of intermittent treatment regimen only because it had previously been shown that they were not liable to develop a recurrence of asthma during the four-day periods without prednisolone. The observation of a significant prednisolone effect in the 8 a.m. recordings for patients on $4 \mathrm{mg}$ of salbutamol is thus not easy to explain. One possible reason is that an effective dose of salbuta$\mathrm{mol}(4 \mathrm{mg}$ ) given the previous evening may have augmented the effect of three days' treatment with prednisolone and produced a further increase in PEFR that was still being substantially maintained at 8 a.m. the following morning. In contrast, those who were not given salbutamol or who received an inadequate dose $(2 \mathrm{mg})$ the previous evening were presumably less well placed to maintain any prednisolone effect during the night, and no such effect was therefore evident in the 8 a.m. figures. The PEFR in all patients with chronic asthma tends to improve later in the day, when differences between the effects of drugs are more difficult to detect than in the morning. This phenomenon might explain why no prednisolone effect was observed in respect of the 6 p.m. and 8 p.m. recordings, even when the 4-mg dose of salbutamol was being given.

This study exemplified some of the problems encountered in long-term clinical trials of bronchodilator drugs. The chief of these is the natural variation of PEFR which occurs during each day, from day to day, and from week to week. As Hume and
Gandevia (1957) pointed out, the apparent efficacy of a bronchodilator is related to the degree of airways obstruction present before it is administered. Thus regular administration of an effective bronchodilator such as salbutamol may serve to accentuate such fluctuations by providing good relief when the asthma is mild and virtually no relief when it is severe. The decrease in PEFR noted in the third and fourth weeks of treatment could reflect natural variations in the severity of asthma. Alternatively, it could represent the beginnings of tolerance to the drug, which has been shown to occur in most patients on long-term treatment with the older oral sympathomimetic drugs.

We conclude from this trial that salbutamol is an effective oral bronchodilator when given for up to four weeks in a dose of $4 \mathrm{mg}$ four times daily to patients with chronic asthma of mild or moderate severity. We have, however, some reservations on whether effective bronchodilatation can be maintained for long periods by this drug or any sympathomimetic agent. A more prolonged trial would be necessary to clarify this point. Side effects were minimal and salbutamol therefore seems to be safe and effective in the dose used in this investigation. We suggest that oral salbutamol can be recommended for use in patients with mild or moderate asthma for periods of up to four weeks.

Our thanks are due to Dr. D. M. Harris, head of medical services, Allen and Hanburys Limited, for providing the salbutamol and placebo tablets used in the trial, to $\mathrm{Mr}$. A. J. Davey for undertaking the statistical analysis, and to Miss Linda Graham for secretarial help.

\section{References}

Brittain, R. T. (1971). Postgraduate Medical fournal, 47 Suppl., p. 11. Choo-Kang, Y. F. J., Simpson, W. T., and Grant, I. W. B. (1969). British Medical fournal, 2, 287.

Choo-Kang, Y. F. J., Parker, S. S., and Grant, I. W. B. (1970). British Medical fournal, 4, 465.

Engelhardt, A., Hoefke, W., and Wick, H. (1961). Arzneimittel Forschung, 11,521 .

Epstein, S. W., Fletcher, C. M., and Oppenheim, E. A. (1969). British Medical Fournal, 1, 223.

Heaf, P. J. D., and Mattila, M. J. (1969). Arzneimittel Forschung, 19, 1927. Hume, K. M., and Gandevia, B. (1957). Thorax, 12, 276.

Kamburoff, P. L., and Prime, F. J. (1970). British fournal of Diseases of the

Chest, 64, 46.
Kennedy, M. C. S., and Simpson, W. T. (1969). British fournal of Diseases of the Chest, $\mathbf{6 3}, 165$.

\title{
Use of Diazoxide in Hypertension with Renal Failure
}

\author{
J. E. F. POHL, H. THURSTON
}

British Medical fournal, 1971, 4, 142-145

\section{Summary}

Treatment with intravenous and oral diazoxide was given to a group of 39 patients suffering from severe drug-resistant hypertension associated with renal impairment. Rapid initial and good long-term control of hypertension was achieved in all cases without the production of clinically significant postural hypotension. The side effects of diazoxide, including its diabetogenic effect, were easily controlled. There was a highly signifi-

Manchester Royal Infirmary, Manchester M13 9WL

J. E. F. POHL, B.SC., M.R.C.P., Lecturer in Therapeutics

H. THURSTON, B.SC., M.R.C.P., Lecturer in Medicine cant improvement in renal function in most patients on long-term oral diazoxide therapy.

Diazoxide may have an important place in both the short- and long-term therapy of resistant hypertension, particularly in association with renal damage.

\section{Introduction}

Severe hypertension associated with impaired renal function requires urgent control. This is often difficult to achieve with conventional sympathetic blocking agents. Total resistance to therapy is not uncommon and if a degree of control is established this may be at the expense of disabling postural hypotension and a further reduction in renal function.

Diazoxide is a non-diuretic bendrothiadiazine with well- 